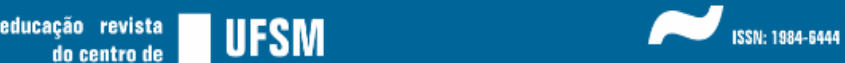

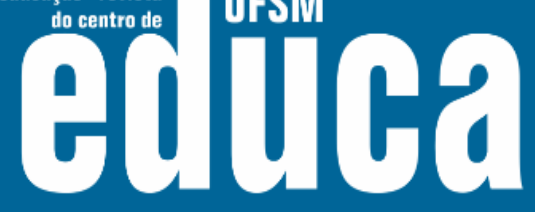

ISSN: 1984-6444 | http://dx.doi.org/10.5902/1984644431778

\section{Ocorrência da síndrome de burnout em um grupo de professores universitários}

\author{
Occurrence of burnout syndrome in a group of university teachers
}

Eliza Penachi

Psicóloga na Secretaria Municipal de Saúde de Pato Branco, Paraná, Brasil.

Mestre em Desenvolvimento Regional pela Universidade Tecnológica Federal do Paraná. elizapenacchi@hotmail.com - https://orcid.org/0000-0003-4229-7845

Edival Sebastião Teixeira

Professor doutor da Universidade Tecnológica Federal do Paraná. Pato Branco, Paraná, Brasil. edival@utfpr.edu.br - https://orcid.org/0000-0002-0712-8109

Recebido em 22 de março de 2018

Aprovado em 14 de fevereiro de 2019

Publicado em 31 de janeiro de 2020

\section{RESUMO}

O artigo analisa a incidência da síndrome de burnout em professores universitários de uma instituição pública federal, sediada no Estado do Paraná. Os dados foram coletados mediante a utilização do Inventário de Sintomas de Stress para Adultos de Lipp (ISSL), do Malasch Burnout Inventory, de um questionário estruturado e de uma entrevista semiestruturada, a qual focalizou a percepção dos participantes em relação aos sintomas vivenciados, bem como as estratégias de enfrentamento do problema por eles utilizadas. Participaram do estudo 69 docentes, sendo $58 \%$ do sexo masculino e $42 \%$ do sexo feminino. A idade variou entre 28 e 67 anos e a experiência docente entre 3 e 39 anos. Os resultados obtidos apontam que $26,09 \%$ da amostra não apresentaram alteração em qualquer das três dimensões avaliadas pelo MBI. Já dentre os demais, $37,68 \%$ apresentaram alteração em uma das três dimensões do burnout e $36,23 \%$ em duas ou nas três dimensões. Foram encontrados níveis alarmantes de exaustão emocional, situação apresentada por $47,82 \%$ da amostra, de despersonalização em $26,08 \%$ da amostra e de reduzida realização pessoal no trabalho em $50,72 \%$ da amostra. Conclui-se, portanto, que além dos casos já identificados com diagnóstico positivo para a síndrome de burnout, a grande maioria dos participantes encontra-se em processo de adoecimento.

Palavras-chave: Síndrome de burnout; Professor; Ensino superior.

\section{ABSTRACT}

The article analyzes the incidence of burnout syndrome in university teachers of a federal public institution, based in the State of Paraná. The data were collected using the Adult Stress Symptom Inventory, the Malasch Burnout Inventory (MBI), a 


\section{F WEM Eulloahá}

ISSN: 1984-6444 | http://dx.doi.org/10.5902/1984644432842

structured questionnaire and a semi-structured interview, which focused on the participants' perception of the symptoms experienced as the coping strategies used by the problem. A total of 69 teachers participated in the study, 58\% of them male and $42 \%$ female. The age ranged from 28 to 67 years and the teaching experience between 3 and 39 years. The results obtained indicate that $26.09 \%$ of the sample did not present alteration in any of the three dimensions evaluated by MBI. Among the others, 37.68\% presented alterations in 1 dimension of burnout and $36.23 \%$ in two or three dimensions. Alarming levels of emotional exhaustion were found in $47.82 \%$ of the sample, $26.08 \%$ in the sample, and $50.72 \%$ in the sample. It is concluded, therefore, that besides the cases already identified with a positive diagnosis for the burnout syndrome, the great majority of the researched population is in the process of becoming ill.

Keywords: Burnout syndrome; Teacher ; Higher education.

\section{Introdução}

A síndrome de burnout é uma resposta a um estado prolongado de estresse, relacionado especificamente ao trabalho. Ou seja, ocorre pela cronificação do estresse laboral, quando os métodos de enfrentamento falharam ou são insuficientes (BENEVIDES-PEREIRA, 2002). Trata-se de um problema que, em geral, acomete caregivers. Isto é, profissionais que atuam na prestação de serviços, no cuidado dos seus usuários. Profissionais acometidos pela síndrome podem manifestar atitudes agressivas para com clientes, alunos ou outros tipos de usuários dos seus serviços (CODO; VASQUES-MENEZES, 1999).

A síndrome é composta por 3 dimensões: Exaustão Emocional (EE), Despersonalização (DE) e Reduzida Realização Profissional (rRP).

A exaustão emocional se refere ao esgotamento físico e mental, e, por isso, é tida como fator central da síndrome e resultante direto do estresse (BENEVIDESPEREIRA, 2002). Nessa situação, os profissionais podem se tornar intolerantes, com humor irritável e pessimistas. Podem, ainda, se mostrarem insensíveis e adotarem rotinas rígidas e inflexíveis de modo a manterem-se distantes de qualquer envolvimento com colegas e clientes, por sentirem que não podem dar mais de si mesmos a nível afetivo (CODO; VASQUES-MENEZES, 1999; RODRIGUES E FRANÇA, 1999). 


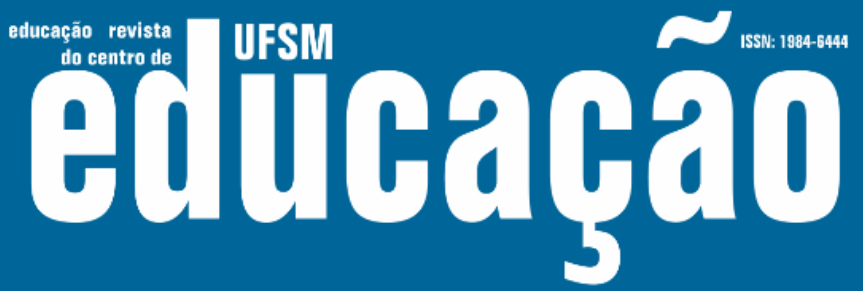

ISSN: 1984-6444 | http://dx.doi.org/10.5902/1984644432842

A despersonalização manifesta-se por sentimentos e atitudes negativas e de cinismo para com as pessoas envolvidas no trabalho, sejam elas colegas ou usuários. Pessoas nessa situação demonstram rigidez afetiva, frieza e indiferença diante das necessidades dos outros, perdendo, portanto, a capacidade de empatia e as relações se tornam coisificadas (CODO; VASQUES-MENEZES, 1999; RODRIGUES; FRANÇA, 1999). Questões relacionadas ao trabalho passam a significar transtornos, problemas para serem resolvidos, as atitudes tornam-se carregadas de intolerância, irritabilidade e ansiedade. (RODRIGUES; FRANÇA, 1999). Trata-se, contudo, de uma tentativa de defesa do indivíduo que, ainda que inadequada, surge como uma alternativa diante do mal-estar experimentado (BENEVIDES-PEREIRA, 2002).

Já a dimensão de reduzida realização profissional se caracteriza pela pouca energia investida nas atividades laborais, pela queda na qualidade e no rendimento e por prejuízos na organização do trabalho como um todo. Diante da deterioração do trabalho realizado, surgem sentimentos de inadequação, decepção e frustração, que comprometem a realização profissional e pessoal, e como consequência ocorre a queda na autoestima podendo chegar ao desenvolvimento de depressão (BENEVIDES-PEREIRA, 2002; RODRIGUES E FRANÇA, 1999; CODO; VASQUESMENEZES, 1999).

Para Codo e Vasques-Menezes (1999), é a combinação do nível em que a pessoa se encontra em cada uma das três dimensões entre si que determina o nível de burnout do indivíduo. Contudo, mesmo a indicação de um nível moderado é sinal de alerta, pois se trata de um indicativo de que o processo de adoecimento já está em curso. Desta forma, o diagnóstico positivo é dado quando ocorrem níveis elevados de exaustão emocional (EE) e despersonalização (DE), e reduzida realização profissional (rRP).

Os sintomas da síndrome podem ser físicos, comportamentais, psíquicos e defensivos, conforme a definição de Benevides-Pereira (2002). 


\section{T HEM 2

ISSN: 1984-6444 | http://dx.doi.org/10.5902/1984644432842

Quadro 1 - Sintomatologia da síndrome de burnout

\begin{tabular}{|l|l|}
\hline \multicolumn{1}{|c|}{ Sintomas Físicos } & \multicolumn{1}{|c|}{ Sintomas Comportamentais } \\
\hline Fadiga constante e progressiva & Negligência ou excesso de escrúpulos \\
Distúrbios do sono & Irritabilidade \\
Dores musculares ou osteomusculares & Incremento da agressividade \\
Cefaleias, enxaquecas & Incapacidade de relaxar \\
Perturbações gastrointestinais & Dificuldade na aceitação de mudanças \\
Imunodeficiência & Perda de iniciativa \\
Transtornos cardiovasculares & Aumento do consumo de substâncias \\
Distúrbios do sistema respiratório & Comportamento de auto risco \\
Disfunções sexuais & Suicídio \\
Alterações menstruais & \\
\hline \multicolumn{1}{|c|}{ Sintomas Psíquicos } & \multicolumn{1}{|c|}{ Sintomas Defensivos } \\
\hline Falta de atenção, de concentração & Tendência ao isolamento \\
Alterações de memória & Sentimento de onipotência \\
Lentificação do pensamento & Perda do interesse pelo trabalho (ou até pelo \\
Sentimento de alienação & prazer) \\
Sentimento de solidão & Absenteísmo \\
Impaciência, Baixa autoestima & Ironia, Cinismo \\
Sentimento de insuficiência & \\
Labilidade emocional & \\
Dificuldade de autoaceitação & \\
Astenia, desanimo, disforia, depressão & \\
Desconfiança, Paranoia & \\
\hline
\end{tabular}

Fonte: Benevides-Pereira (2002)

A pessoa com síndrome de burnout não necessariamente apresenta todos os sintomas, pois estes podem variar de acordo com características individuais, assim como devido a fatores ambientais. Desta forma, pode haver variações de acordo com os níveis em que a pessoa se encontra no desenvolvimento da síndrome (BENEVIDES-PEREIRA, 2002).

Benevides-Pereira (2002) chama atenção para o diagnóstico diferencial entre depressão e burnout, pois ambos têm em comum a disforia e o desânimo. Contudo, quando acometida pela síndrome de burnout a pessoa percebe o trabalho como desencadeante do processo e prevalência de sentimentos de desapontamento e tristeza, enquanto que na depressão a pessoa se encontra em maior submissão à letargia e a sentimentos de culpa e derrota.

A síndrome de burnout tem causa multifatorial, sendo que os possíveis desencadeadores consistem em uma combinação de características pessoais, do tipo de atividade realizada e de variáveis oriundas da instituição. A combinação de fatores 


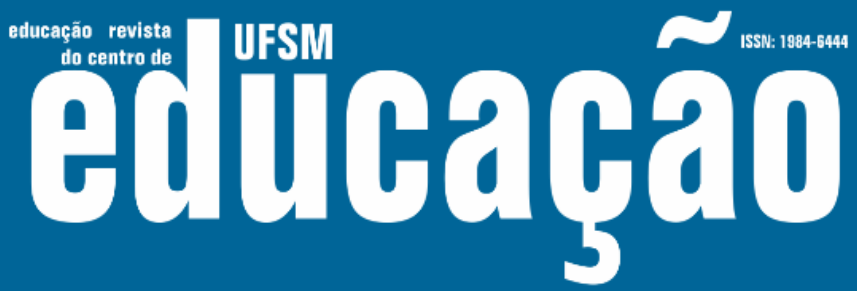

ISSN: 1984-6444 | http://dx.doi.org/10.5902/1984644432842

das três categorias pode mediar ou facilitar o processo de adoecimento (BENEVIDESPEREIRA, 2002).

Pesquisas sobre a incidência da síndrome de burnout têm demonstrado que esse problema tem sido recorrente entre professores, como se observa nos trabalhos de pesquisadores tais como Codo e Vasques-Menezes (1999), Benevides-Pereira (2002), Carlotto (2002), Oliveira e Cardoso (2011), Dallacosta (2014) e Borges e Lauxen (2016). Em geral, o resultado desses estudos tem apontado que a incidência de burnout é maior entre professoras do que entre professores, maior entre profissionais mais jovens, com menos tempo de experiência no magistério, entre os menos satisfeitos com a carreira (DALLACOSTA, 2014) e, quase que paradoxalmente, entre os mais motivados. Codo e Vasquez-Menezes (1999), por exemplo, alegam que quando o professor, devido à baixa realização no trabalho, não consegue alcançar os objetivos a que se propõe, vai sendo tomado pouco a pouco por sentimentos de impotência e incapacidade passando a se avaliar negativamente e, como consequência, seu trabalho vai perdendo o sentido que tem para si.

Portanto, o que os resultados de diversas pesquisas, como as mencionadas neste artigo, indicam que o ambiente de trabalho na universidade pública vem se tornando cada vez mais ansiogênico. Com efeito, tem sido observada uma intensificação do trabalho docente nas universidades públicas decorrente da ampliação de vagas na última década, por um lado e, por outro, da adesão do Estado a modelos de gestão tipicamente empresariais focados quase que exclusivamente na produtividade (MOROSINI, 2000; SANTOS, 2004; SILVA JUNIOR; SGUISSARDI, 2013).

Conforme Santos (2004), trata-se de um processo de ajuste estrutural em que o setor educacional fica preso a critérios de eficiência e eficácia tipicamente empresariais. Esse olhar avaliativo do Estado resulta da adoção de políticas educacionais na década de 1990 (MOROSINI, 2000; SILVA JUNIOR; SGUISSARDI, 2013) ajustadas a interesses econômicos que tornaram a racionalidade mercantil o cerne de políticas públicas, em cujos resultados encontram-se a intensificação do trabalho do professor e o empobrecimento de suas relações (SILVA JUNIOR; SGUISSARDI, 2013). 


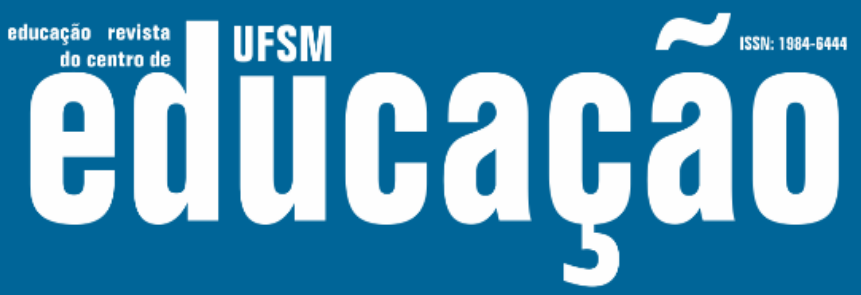

ISSN: 1984-6444 | http://dx.doi.org/10.5902/1984644432842

As demandas impostas aos professores só aumentaram com todo o processo de expansão e de mudanças de que fala Morosini (2000). Às atividades de ensino e pesquisa que já exigem considerável esforço dos docentes, foram acrescentadas outras demandas tais como a captação de fundos para o financiamento de suas pesquisas, o estabelecimento de parcerias com empresas privadas, desenvolver soluções científicas para o atendimento de demandas locais, regionais e nacionais, e atender a uma clientela discente com necessidades para as quais os docentes nem sempre estão preparados (PEREIRA, 2009).

Assim, as reformas que acabaram por impor um olhar avaliativo do Estado forçam a universidade para que convirja com modelos sociais vigentes, buscando atender às necessidades de um mercado crescente, alcançar eficiência seguindo padrões internacionais e organizar-se como que em linhas de produção (CARTOLLO, 2002). E é nesse contexto de cultura da performatividade e de intensificação do trabalho docente universitário que, conforme Santos (2004), está sendo forjada a subjetividade dos profissionais da educação dos dias atuais. Profissionais, diga-se, que vêm adoecendo, devido, em parte, a tantas mudanças no seu fazer cotidiano exigidas pelo alinhamento do sistema educacional ao produtivismo e à precarização do trabalho típicos do capitalismo atual (LEITE, 2011).

O artigo ora apresentado analisa a incidência da síndrome de burnout em professores universitários de uma instituição pública federal localizada no Sul do Brasil, bem como as estratégias de enfrentamento utilizadas e a percepção desses docentes em relação a esse problema.

\section{Metodologia}

Para a coleta de dados foram utilizados 3 procedimentos. Primeiramente foi aplicado o Inventário de Sintomas de Stress para Adultos de Lipp (ISSL) e o Malasch Burnout Inventory (MBI - ED). Esses instrumentos foram utilizados para a identificação da incidência de estresse entre os participantes, bem como eventuais evoluções negativas para a síndrome de burnout. Nesse sentido, o MBI-ED foi utilizado justamente para a avaliação dos níveis de burnout. 


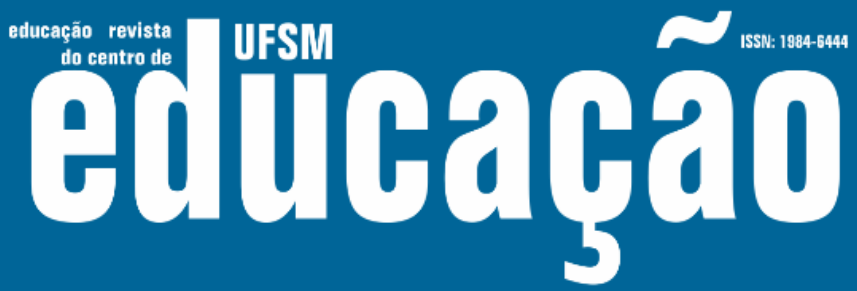

ISSN: 1984-6444 | http://dx.doi.org/10.5902/1984644432842

O ISSL tem sido de ampla escolha na investigação sobre estresse em adultos no Brasil, como se pode observar nos trabalhos de Guimarães (2006), Malagris e Fiorito (2006), Malagris et a.I (2009), Thomaz, Rocha e Neto (2011) Azambuja (2013). É composto por seis quadros, relativos às fases do estresse tal como descritas por Lipp (2014): alerta, resistência, quase-exaustão e exaustão.

O MBI-ED consiste na adaptação do Malasch Burnout Inventory para ser utilizado especificamente com educadores. Trata-se de um questionário de autoinforme para ser respondido através de uma escala do tipo likert de 7 pontos, no qual "0" corresponde a "nunca" e "6" como "todos os dias" (BENEVIDES-PEREIRA, 2002 p.73). O instrumento é composto por 15 itens, dos quais cinco se referem à dimensão de Exaustão Emocional, quatro à dimensão Despersonalização e seis à dimensão de Reduzida Realização Profissional.

Esse instrumento é amplamente utilizado e reconhecido em todo o mundo nos estudos dedicados à síndrome de burnout (CARLOTTO, 2002) e tem sido um instrumento de ampla escolha em muitos estudos também no Brasil, a exemplo dos trabalhos de Carlotto (2002), Carlotto e Câmara (2004), Benevides-Pereira (2002), Borges e Lauxen, (2016), Dallacosta, (2014).

O segundo procedimento consistiu na aplicação de um questionário estruturado, cujo objetivo foi levantar dados sociodemográficos, identificar os principais agentes estressores tais como são percebidos pelos participantes da pesquisa, bem como investigar se os mesmos se utilizam de alguma estratégia de enfrentamento diante destes estressores.

O terceiro procedimento consistiu em entrevista, cujo objetivo era apreender a visão dos participantes acerca de três aspectos: percepções em relação aos agentes estressores identificados, percepções em relação aos sintomas vivenciados e percepções em relação às estratégias de enfrentamento que utiliza.

O convite para a participação da pesquisa foi enviado via comunicação interna da instituição para todos os docentes do campus, que segundo dados fornecidos pela Coordenadoria de Gestão de Recursos Humanos da instituição, em outubro de 2016 eram 430 professores, de ambos os sexos entre efetivos concursados e temporários. 


\section{F WEM oltuará

ISSN: 1984-6444 | http://dx.doi.org/10.5902/1984644432842

Participaram da pesquisa todos os que aceitaram participar e que responderam integralmente aos questionários. O terceiro instrumento, a entrevista, foi aplicado aos $10 \%$ dos respondentes que apresentarem maiores índices de estresse e de síndrome de burnout e aos 10\% com menores índices ou ausência completa dos problemas.

Os dados foram coletados entre maio e junho de 2017 e o projeto foi submetido e aprovado por Comitê de Ética em Pesquisa Envolvendo Seres Humanos.

\section{Resultados e discussão}

Participaram voluntariamente da pesquisa 69 professores do Campus Pato Branco da Universidade Tecnológica Federal do Paraná. A amostra foi constituída por $58 \%$ de professores do sexo masculino e $42 \%$ do sexo feminino, com idades variando entre 28 e 67 anos. O tempo de experiência docente variou de 3 até 39 anos.

Os resultados obtidos demonstram que $13,04 \%(n=9)$ da amostra atinge os critérios para diagnóstico positivo de burnout, ou seja, altos níveis de exaustão emocional e despersonalização associados a reduzida realização pessoal. Dentre esse grupo encontram-se 5 professoras (55,56\%) e 4 professores (44,44\%). Todavia, levando-se em conta que a amostra total foi constituída 58,00\% de homens e 42,00\% de mulheres, os resultados parecem indicar que não existem diferenças consideráveis entre gêneros, há professores e professoras acometidos pela síndrome na instituição pesquisada.

Analisando-se os dados obtidos em cada uma das sub-escalas do MBI - ED, observou-se que o quadro na instituição pesquisada parece grave. Foram encontrados índices muito altos de exaustão emocional (EE) em 47,8\% dos professores, níveis altos de despersonalização (DE) em $26,1 \%$ e reduzida realização pessoal profissional (rRP) em $50,7 \%$ da amostra.

Os resultados apontaram que apenas $26,09 \%$ da amostra ( $n=18$ ), não apresentaram alteração em qualquer das três dimensões avaliadas. Já dentre os demais, $37,68 \%(n=26)$ apresentaram alteração em uma das três dimensões do burnout e $36,23 \%(n=25)$ em duas ou nas três dimensões. 


\section{Aillbapẫ

ISSN: 1984-6444 | http://dx.doi.org/10.5902/1984644432842

Na figura 1, estão distribuídos os docentes com alteração em duas ou 3 das dimensões do burnout. Nos espaços de interseção foram distribuídos os professores que apresentam índices considerados altos em mais de um eixo. No centro da figura que faz interseção entre os três eixos foram incluídos os professores com alteração em todas as dimensões.

Figura 1 - Distribuição de professores em cada dimensão de burnout em números absolutos

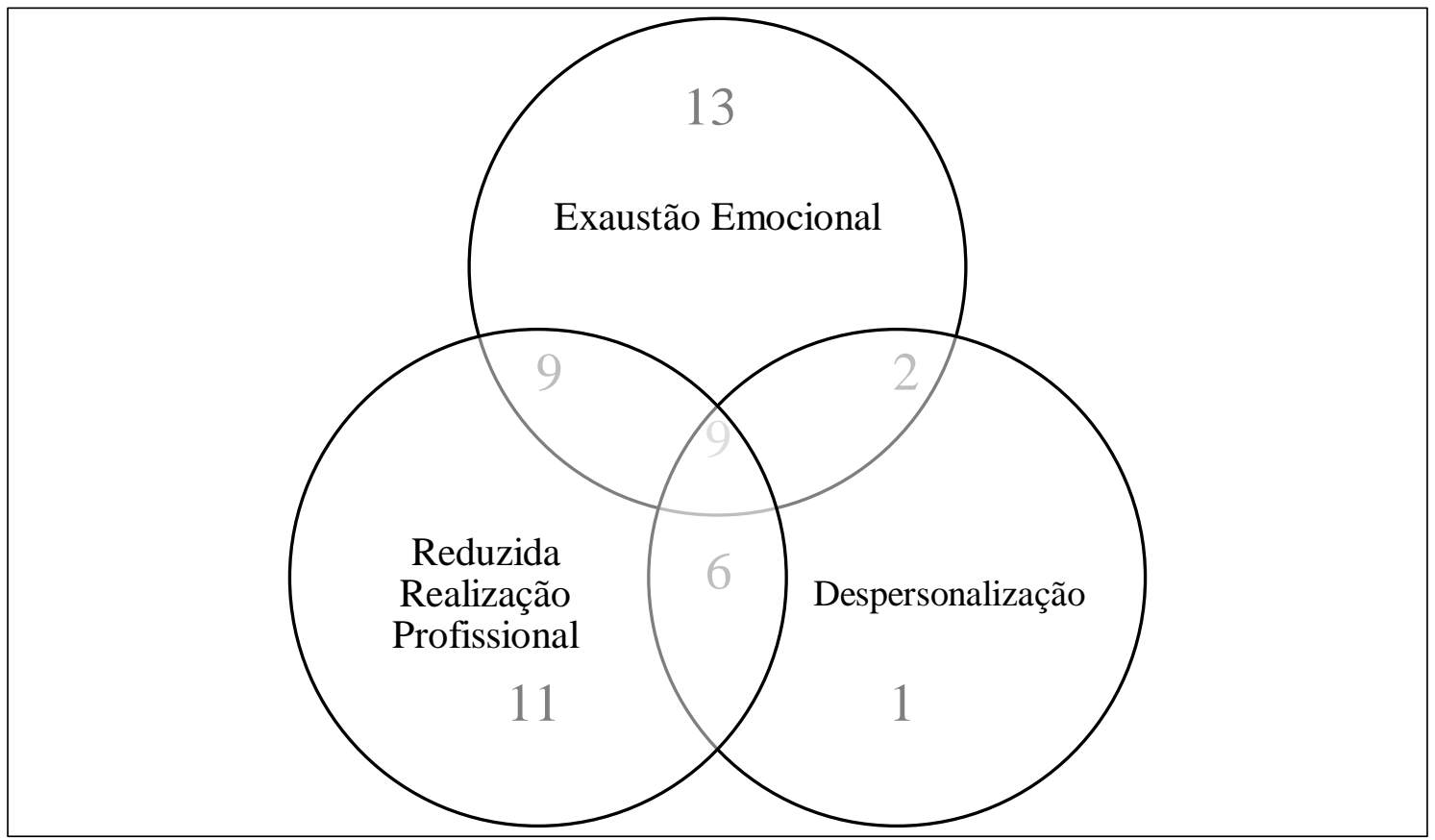

Fonte: dados obtidos na pesquisa

Assim, os resultados obtidos demonstram a incidência do problema na instituição pesquisada, considerando-se que apenas 26,09\% dos participantes não apresentou qualquer alteração em nenhuma das três escalas. Os demais 73,91\% apresentou alteração em duas ou 3 dimensões, sendo que 9 dois quais, 4 professores e 5 professoras, têm diagnóstico positivo para a síndrome de burnout.

No quadro 2 são apresentados e caracterizados os 25 participantes que apresentaram alteração em duas ou três subescalas do MBI-ED. 


\section{N Wsm

ISSN: 1984-6444 | http://dx.doi.org/10.5902/1984644432842

Quadro 2 - Caracterização dos professores com alteração em duas ou 3 dimensões da síndrome

\begin{tabular}{|c|c|c|c|c|c|c|}
\hline Sexo & Idade & Estado civil & Filhos & $\begin{array}{l}\text { Experiência } \\
\text { (anos) }\end{array}$ & $\begin{array}{c}\text { Carga } \\
\text { horária } \\
\text { (horas) }\end{array}$ & MBI-ED \\
\hline $\mathrm{F}$ & 54 & União estável & 3 & 23 & 40 & Burnout \\
\hline $\mathrm{F}$ & 38 & Divorciada & 2 & 9 & 40 & Burnout \\
\hline M & 54 & Casado & 3 & 23 & 40 & Burnout \\
\hline$F$ & 44 & Solteira & 0 & 19 & 40 & Burnout \\
\hline M & 42 & Casado & 2 & 14 & 40 & Burnout \\
\hline$F$ & 43 & União estável & 1 & 15 & 40 & Burnout \\
\hline M & 35 & Casado & 0 & 6 & 50 & Burnout \\
\hline $\mathrm{F}$ & 34 & União estável & 0 & 3 & 40 & Burnout \\
\hline M & 51 & Casado & 1 & 15 & 40 & Burnout \\
\hline M & 43 & Casado & 2 & 16 & 40 & $E E+r R P$ \\
\hline$F$ & 37 & União estável & 0 & 9 & 40 & $E E+r R P$ \\
\hline M & 57 & Casado & 3 & 23,5 & 40 & $E E+r R P$ \\
\hline M & 32 & Casado & 1 & 11 & 40 & $E E+D E$ \\
\hline$F$ & 35 & Casada & 1 & 12 & 50 & $E E+r R P$ \\
\hline M & 56 & Casado & 2 & 24 & 40 & $\mathrm{DE}+\mathrm{rRP}$ \\
\hline$F$ & 52 & Solteira & 0 & 10 & 40 & $E E+r R P$ \\
\hline M & 41 & Casado & 1 & 5 & 50 & $\mathrm{EE}+\mathrm{rRP}$ \\
\hline M & 42 & Casado & 1 & 10 & 40 & $\mathrm{DE}+\mathrm{rRP}$ \\
\hline M & 44 & Casado & 1 & 20 & 40 & $E E+r R P$ \\
\hline M & 50 & Casado & 2 & 25 & 40 & $\mathrm{DE}+\mathrm{rRP}$ \\
\hline$F$ & 33 & Solteira & 0 & 6 & 40 & $\mathrm{EE}+\mathrm{DE}$ \\
\hline M & 63 & Casado & 1 & 27 & 40 & $E E+r R P$ \\
\hline M & 37 & Casado & 1 & 10 & 40 & $E E+r R P$ \\
\hline M & 59 & Casado & 4 & 24 & 40 & $\mathrm{DE}+\mathrm{rRP}$ \\
\hline$M$ & 40 & Casado & 3 & 9 & 40 & $\mathrm{DE}+\mathrm{rRP}$ \\
\hline
\end{tabular}

Fonte: dados obtidos na pesquisa 


\section{工 Eutloará

ISSN: 1984-6444 | http://dx.doi.org/10.5902/1984644432842

Como pode ser observado no quadro, a grande maioria está casada ou em união estável e tem filhos. Nesse grupo, o tempo médio de experiência docente encontrado foi de 14 anos e a idade média 44,6 anos.

Os resultados obtidos demonstram claramente que o adoecimento por burnout está se distribuindo equitativamente entre homens e mulheres na instituição pesquisada, o que vem contrariando a literatura, a qual da conta da predominância da síndrome em mulheres. Ainda que em números absolutos o diagnóstico positivo tenha sido atribuído a mais professoras que professores, há que se levar em conta que a distribuição proporcional de todos os 69 participantes apresenta ligeira maioria masculina, sendo $58 \%$ deles e $48 \%$ delas. Mas, quando se observa apenas os 25 casos de adoecimento diagnosticado ou em processo avançado de adoecimento, encontram-se 16 professores, correspondendo a 64\% desse grupo, e 9 professoras, ou $36 \%$ desse grupo.

Da mesma forma, em sentido oposto ao apontado pela literatura, entre os professores pesquisados a predominância da síndrome não está propriamente ocorrendo em mulheres jovens e com pouco tempo de experiência profissional. Com efeito, tomando-se os 9 casos diagnosticados, observa-se que entre as mulheres a idade média encontrada foi de 42,6 anos e o tempo média de experiência docente foi de 13,8 anos. Já dentre os homens, a idade média encontrada foi de 45,5 anos e com 14,5 anos de experiência docente, em média. Por conseguinte, os resultados obtidos demonstram que, dentre o grupo de participantes da pesquisa, o adoecimento por burnout está acometendo professores e professoras já próximos da metade da sua carreira docente universitária. Ou seja, pessoas maduras em idade e em experiência profissional.

Nas entrevistas a experiência foi citada várias vezes como um fator importante que auxilia no enfrentamento das dificuldades na carreira. $O$ que pode ser observado nos excertos a seguir:

Eu não sei se talvez isso conta, mas acredito que os anos de experiências conte, já enfrentei situações muito estressoras [...] talvez eu tenha aprendido desde criança, com o meu pai e minha mãe, a se virar em situações difíceis, aquilo que é possível resolver, resolver, aquilo que não é possível resolver, fazer da melhor forma possível e não entrar em atrito desnecessários (Participante 35). 


\section{$\sim=$ Eulloabुa}

ISSN: 1984-6444 | http://dx.doi.org/10.5902/1984644432842

O que facilitou foi a experiência, no início não era muito fácil, aí tinha reclamações de alunos, didática, mas foi um ano, não sei se o pessoal se acostumou comigo ou se eu fui melhorando, talvez os dois, foi melhorando e cada vez menos e menos e menos (Participante 67).

Quando a gente começa a dar aula, você tem uma ideia, eu pretendo ser rigorosa os prazos são esses, não vou abrir, aí você vai adaptando, no outro ano você já está diferente. Quando você começa a dosar isso, você sente que melhora essa relação, até mesmo da questão da indisciplina, eu percebo que quando você bate muito de frente com o aluno, você acaba não tendo o retorno que você esperava. Eu converso muito com os professores mais experientes, sobre situações (Participante 65).

A experiência pode mesmo propiciar maturidade e maior habilidade nos trabalhos, o que pode ser um fator que facilita o controle do estresse e previna a ocorrência do burnout, e alguns participantes têm esta percepção. Porém, ao visualizar a quadro 2 é possível verificar que entre os casos mais graves estão justamente professores experientes. Por conseguinte, os resultados obtidos sugerem que somente a experiência profissional não é suficiente para a garantia da saúde dos docentes e que diversos outros fatores estão influenciando negativamente nesse aspecto na instituição pesquisada.

Durante as entrevistas, alguns participantes relataram diretamente sintomas que têm percebido em si. A Participante 28, por exemplo, afirmou: "tenho a percepção, na sala de aula, que tenho um esgotamento mental. Às vezes eu não consigo lembrar uma palavra, me sinto lenta”. Esta fala evidencia sintomas relativos a dificuldades de atenção, de memória e de lentificação do pensamento, os quais são relativos à dimensão de exaustão emocional da síndrome de burnout.

Com efeito, essa participante apresentava alteração nas três dimensões do burnout, fato esse que sustenta um diagnóstico positivo para síndrome. Em sua fala observa-se, também, a ocorrência de uma espécie de visão negativa acerca de tudo o que era comentado em relação ao trabalho, usando frases como: "O que eu vejo é que os professores já vêm mau humorados pra uma reunião"; "Não tem como resolver isso." (Participante, 28). Tais frases podem caracterizar sintomas de burnout como pessimismo, sentimentos e atitudes negativas em relação ao trabalho e às pessoas. Características de despersonalização e exaustão emocional. 


\title{
$\sim$ Ẽtloapga
}

ISSN: 1984-6444 | http://dx.doi.org/10.5902/1984644432842

Outro professor diagnosticado com burnout também demostrou em sua entrevista características descritas como sintomas da síndrome. Na fala a seguir é possível identificar o esgotamento do docente:

\begin{abstract}
Uma coisa que eu acho importante colocar, é que teve períodos que eu tinha muito mais demandas de trabalho. O que eu sinto hoje é que eu estou desanimado, minha intensidade de trabalho está diminuindo e eu não estou melhorando a minha qualidade de vida, no sentido de eu estar mais harmônico, mais relaxado. Antes eu tinha muito mais demandas e eu resistia. Hoje, eu tenho muito menos atribuições, comparando com outros momentos, mas sinto que tenho menos produtividade. [...]

a gente acaba se envolvendo com diversas atividades e acaba que eu não faço um trabalho bem feito, o sentimento que eu tenho hoje é que as minhas aulas, são aulas... bom, até que as aulas estão mais ou menos. De que a minha pesquisa é medíocre, medíocre no sentido de ser mediana, a minha extensão é medíocre, eu não faço nada muito qualificado. É a percepção que eu tenho (Participante 32).
\end{abstract}

A fadiga e o sentimento de insuficiência descritos pelo docente são sintomas da síndrome de burnout, conforme Benevides-Pereira (2002). Ademais, nessa fala é possível observar a ocorrência de diversos sintomas. Nota-se que ele demonstra pouca energia para investir no trabalho, ocasionando queda na qualidade e no rendimento e que, diante da deterioração do trabalho, surgem sentimentos de inadequação, frustração, e a realização profissional e pessoal ficam comprometidas e como consequência ocorre a queda na autoestima, passando a se avaliar negativamente.

Por outro lado, as medidas que esse docente vem aplicando devido a ter percebido o seu esgotamento, têm surtido efeitos e os sintomas físicos estão bem controlados. Sobre o enfrentamento, sobre estar em processo de mudanças, se submetendo a processo terapêutico e suporte medicamentoso o professor disse:

\footnotetext{
Por ter decidido, um tempo atrás, desacelerar o trabalho, porque eu estava com sobrepeso, sedentarismo e já estava começando com algum problema coronário. Estava com uma combinação de fatores para ter uma saúde ruim. Aquele nível de estresse tão grande, foi até bom, porque a pressão foi tão grande que fez eu ter essa atitude, de comprar uma bicicleta, de procurar um psicólogo, me alimentar melhor. A pressão foi tão grande que eu pensei que se eu seguisse nesse ritmo, meu filho nem ia me conhecer, então a minha saúde está boa. Ainda estou buscando, essa capacidade de não me irritar, eu estou evoluindo nisso, mas já melhorei (Participante 32).
} 


\section{- Tusm Eutinará

ISSN: 1984-6444 | http://dx.doi.org/10.5902/1984644432842

Outro dado importante é que entre os professores entrevistados, dentre o grupo dos maiores índices, foi possível perceber a incidência de sintomas físicos relacionados ao burnout. O Participante 18, por exemplo, estava com uma inflamação no dente, visível devido ao inchaço em seu rosto e que também foi comentado por ele próprio, que argumentou dizendo que adquiriu o habito de ranger os dentes e que o faz com tanta frequência e intensidade que um dente havia inflamado e o professor havia retornado há pouco de um atendimento odontológico. Já a Participante 28, já mencionada anteriormente, enquanto respondia à entrevista espirrava e tossia constantemente e também comentou sobre a própria situação, afirmando que estava adoentada há dias. Alguns sintomas relacionados à baixa imunidade do organismo estavam aparentes em alguns professores.

Ainda dentre os docentes com diagnóstico positivo para burnout, encontra-se a Participante 39, a qual está fazendo doutorado sem afastamento, o que em parte justifica seu quadro:

Eu sinto a imunidade muito baixa, rinite, cansaço, e eu engordei $6 \mathrm{Kg}$ este ano, mas a minha expectativa é que é uma fase e que vai passar [...]. Às vezes, acordo 3, 4 horas da manhã, daí consigo dormir lá pelas 6 ou 7 horas, daí tenho que levantar, daí passo o dia inteiro cansada.

$\mathrm{Na}$ fala da Participante 39 é possível identificar vários sintomas psicológicos e físicos relacionados à síndrome de burnout: alterações no sono, cansaço e sintomas físicos decorrentes da baixa imunidade. Mas essa participante também relatou problemas familiares e mesmo um acúmulo de problemas que vem enfrentando nos últimos anos, inclusive de ordem judicial, fatores múltiplos, portanto, que podem estar contribuindo para o desenvolvimento da doença.

Um fator comum entre os professores entrevistados com os maiores índices de burnout é a grande quantidade de reclamações e descontentamentos relativos à instituição e ao trabalho.

O desenvolvimento da síndrome de burnouté atribuído à confluência de fatores organizacionais, relativos às relações no trabalho, associados a características do tipo de atividade realizada e ao perfil de personalidade dos indivíduos (BENEVIDESPEREIRA, 2002). Vários estudos já tentaram traçar um perfil a respeito de quais os perfis mais acometidos pelo burnout. Codo e Vasques-Menezes (1999) sugerem que 


\section{Autuaŗão}

ISSN: 1984-6444 | http://dx.doi.org/10.5902/1984644432842

wokaholics (profissionais altamente comprometidos e dedicados ao trabalho) assim como a falta de uma rede social de apoio são fatores frequentemente associados aos burnout. Os docentes de uma instituição tecnológica federal possivelmente podem ser descritos como profissionais dedicados e altamente comprometidos, pois sabe-se que o caminho trilhado até alcançar este lugar social não é simples ou curto. E talvez este seja um dos motivos pelos quais os dados são tão altos.

Dentre os 69 participantes da pesquisa, dois professores, inadvertidamente, responderam ao mesmo instrumento duas vezes e em datas distintas. Esse fato é um indicador, tendo em vista que ambos os docentes que responderam em duplicidade apresentavam níveis elevados de estresse e alterações significativas na avaliação da síndrome de burnout. Trata-se dos participantes 4 e 31 .

O Participante 4 declarou uma carga horária de 50 horas semanais, e de acordo com as respostas relativas à sua primeira resposta aos instrumentos de coleta de dados, a dimensão de exaustão emocional, do burnout, apresentava alteração. Exatamente 31 dias depois, o mesmo professor atendeu à solicitação novamente e respondeu ao questionário mais uma vez. As respostas obtidas neste momento indicaram alterações em dois dos três eixos, exaustão emocional e desrealização profissional. Considerando as duas participações do docente é possível avaliar o quanto o quadro do professor se intensificou, mais próximo ao final do semestre a situação do professor já era mais grave e o mesmo apresentava baixa realização profissional além da exaustão emocional, já identificada 31 dias antes.

Por sua vez, a Participante 31 declarou uma carga horária de 40 horas semanais. Na primeira participação seu resultado no MBI-ED deu alteração nas três dimensões do burnout. Exatos 28 dias depois, a participante respondeu ao MBI-ED novamente, com o mesmo resultado.

Responder inadvertidamente um mesmo instrumento por duas vezes em um período de aproximadamente um mês é um dado importante, tendo em vista que ambos os participantes que o fizeram apresentavam níveis elevados de estresse e de burnout. Assim, o dado em questão parece indicar problemas relativos à atenção e à memória, os quais são sintomas relacionados ao burnout (Benevides-Pereira, 2002). 


\section{Autuaŗão}

ISSN: 1984-6444 | http://dx.doi.org/10.5902/1984644432842

Em geral, os docentes participantes da pesquisa se queixam da elevada carga de tarefas burocráticas que têm de desenvolver, das excessivas cobranças por publicações, projetos e demais, sobretudo dentre os que atuam na pós-graduação. Ademais, queixam-se da falta de estrutura e dos processos de avaliação de desempenho. Isto é, que estão sendo muito cobrados, mas pouco reconhecidos, em parte pela instituição e em parte pela sociedade em geral.

\section{Considerações finais}

Os resultados obtidos neste estudo demonstram a ocorrência da síndrome de burnout na instituição pesquisada em níveis alarmantes. Os sinais percebidos e os sintomas relatados nas entrevistas são corroborados pelos dados obtidos pelo ISSL e o MBI-ED.

Os participantes da pesquisa fazem parte de uma população altamente qualificada, em sua grande maioria doutores e dentre os quais uma boa quantidade com experiência internacional e pós-doutorado. Esse grupo dedicou muito esforço e anos em sua formação e, ao que se supõe, atuam naquilo que sempre desejaram para sua vida profissional, a produção e a transmissão do conhecimento.

A literatura tem mostrado que a síndrome de burnout acomete trabalhadores altamente motivados e perfeccionistas. Alguns trabalhos também relacionam o burnout com discrepâncias entre 0 investimento do trabalhador em relação ao reconhecimento e resultados que recebe em contrapartida. E isto, os resultados obtidos sugerem, pode ser parte do problema na instituição pesquisada.

Mas, para além dos fatores organizacionais, há que se levar em conta o momento histórico ora vivido em que se encontra em curso um processo de intensificação do trabalho docente na universidade pública, que obriga o professor a atuar sob ditames de uma entidade abstrata chamada "mercado", mas cujos resultados se fazem ver intensamente.

Paralelamente, decorrente das políticas educacionais alinhadas ao mercado, vem ocorrendo sistematicamente um processo de precarização do trabalho docente nas universidades públicas, cujos reflexos se observam pelo achatamento dos 


\section{Dism Eulloabato}

ISSN: 1984-6444 | http://dx.doi.org/10.5902/1984644432842

salários, pela retirada de direitos conquistados arduamente, pelo corte de verbas, pela não reposição de pessoal ante aposentadorias ou outras formas de desligamento.

Além disso, também está em curso uma campanha de desqualificação do serviço público em geral, do setor da educação em especial. Assim, os problemas nesse âmbito deixam de ser originados nos desmandos da gestão pública, quase sempre feitos em benefício de grupos minoritários mas poderosos, e passam a ser creditados aos próprios servidores públicos que têm sido considerados pelos governos e por setores da iniciativa privada como o entrave a ser eliminado para que se alcance a propagandeada qualidade educacional, a qual é consubstanciada na resposta a avaliações estandardizadas e na empregabilidade do egresso.

Uma universidade pública federal aparentemente é um dos lugares em que se chega após uma longa caminhada de graduação, pesquisas, mestrado, experimentos, bancas, qualificações, congressos, publicações, doutorado, muito estudo e maratona de concursos. Paradoxalmente estranha que o que poderia ser um bom lugar para o desenvolvimento da carreira de um docente não esteja se constituindo como um lugar ao sol, no qual se desejou tanto chegar, mas que quando é alcançado não proporcione a tão sonhada realização profissional e ainda gere em muitos o adoecimento.

\section{Referências}

AZAMBUJA, Débora Aparecida Ramos. Um estudo longitudinal acerca das variáveis inferentes na qualidade de vida e estresse de universitários do curso de psicologia. In: CONIC-SEMESP. 1. 2013, Campinas. Anais conic-semesp, Faculdade Anhanguera de Campinas. 2013.

BENEVIDES-PEREIRA, Ana Maria Teresa (Org.) Burnout: quando o trabalho ameaça o bem-estar do trabalhador. São Paulo: Casa do Psicólogo, 2002.

BORGES, Rosimar Souza dos Santos; LAUXEN, Iarani Augusta Galúcio. Burnout e fatores associados em docentes da Universidade Federal do Rio de Janeiro. Saúde em Redes. Rio de Janeiro; v.2 n.1 p. 97 - 116, 2016

CARLOTTO, Mary Sandra. Síndrome de Burnout e satisfação no trabalho: um estudo com professores universitários. In: Ana Maria Teresa Benevides-Pereira. Burnout: Quando o trabalho ameaça o bem-estar do trabalhado. São Paulo: Casa do Psicólogo.2002. p.187-212. 


\section{त्turm Eutloghat}

ISSN: 1984-6444 | http://dx.doi.org/10.5902/1984644432842

CARLOTTO, Mary Sandra; CAMARA, Sheila Gonçalves. Análise fatorial do Maslach Burnout Inventory (MBI) em uma amostra de professores de instituições particulares. Psicologia em estudo. Maringá vol.9, n.3. p.499-505, 2004.

CODO, Wanderley. (Org.). Educação: carinho e trabalho. Petrópolis: Vozes, 1999.

CODO, Wanderley; VASQUES-MENEZES, lône. O que é Burnout? In: CODO, Wanderley (coord.). Educação: carinho e trabalho. Petrópolis, RJ: Vozes, 1999.

DALLACOSTA, Fabiana Meneghetti. Avaliação do nível de satisfação no trabalho e dos sintomas de burnout em docentes da área da saúde. Rio Grande do Sul: Programa de Pós-Graduação da Faculdade de Medicina da Pontifícia Universidade Católica. 2014.

RODRIGUES, Avelino Luiz; FRANÇA, Ana Cristina Limongi. Stress e trabalho: uma abordagem psicossomática. 2. Ed. São Paulo: Atlas, 1999

GUIMARÃES, Katia Burle Santos. Incidência de estresse e formação médica. Revista de Psicologia, UNESP São Paulo, 2006.

LEITE, Janete L. As transformações no mundo do trabalho, reforma universitária e seus rebatimentos na saúde dos docentes universitários. Universidade e Sociedade. Ano XXI, n. 48, p. 84-97. DF: ANDES, jul. 2011.

LIPP, Marilda Emmanuel Novaes. Manual do inventário de sintomas de estresse para adultos de Lipp (ISSL). 3. ed. Revisada. São Paulo: Casa do Psicólogo, 2014.

MASLACH, Chistina; JACKSON, Susan E. Maslach Burnout Inventory. 2. ed. Palo Alto, CA: Consulting Psychologist Press, 1986.

MALAGRIS, Lúcia Emmanoel Novaes; FIORITO, Aurineide Canuto Cabraíba. Avaliação do nível de stress de técnicos da área de saúde. Estudos de Psicologia, Campinas, v. 23, n. 4, p. 391-398, dez. 2006.

MALAGRIS, Lúcia Emmanoel Novaes. et al. Níveis de estresse e características sociobiográficas de alunos de pós-graduação. Psicologia em Revista, Belo Horizonte, v. 15, n. 1, p. 184-203, abr. 2009.

MOROSINI, Marília Costa. Docência Universitária e os Desafios da Realidade Nacional. In: MOROSINI, Marília Costa (Org.). Professor do Ensino Superior: identidade, docência e formação. Brasília: Instituto Nacional de Estudos e Pesquisas Educacionais, 2000.

OLIVEIRA, Maria das Graças; CARDOSO, Cármen. Stress e trabalho docente na área de saúde. Estudos de Psicologia. Campinas, vol.28, n.2, p. 135-141, 2011.

PEREIRA; Elisabete Monteiro de Aguiar. A Universidade Da Modernidade Nos Tempos Atuais. Avaliação, Sorocaba, SP, v. 14, n. 1, p. 29-52, mar. 2009. 


\section{usm Ẽtloapga}

ISSN: 1984-6444 | http://dx.doi.org/10.5902/1984644432842

SANTOS, Lucíola Licínio de Castro Paixão. Formação de professores na cultura do desempenho. Educação e Sociedade, Campinas, v. 25, n. 89, p. 1145-1157, set./dez 2004.

SILVA JÚNIOR João dos Reis; SGUISSARDI, Valdemar. Universidade Pública Brasileira no Século XXI Educação superior orientada para o mercado e intensificação do trabalho docente. Espac. blanco, Ser. indagaciones, Tandil, v. 23, n. 1, jun. 2013

THOMAZ, Patrícia Ester; ROCHA, Luciano Baracho; NETO, Vicente Machado. Estresse em estudantes de engenharia. Momento - Diálogos em educação, Rio Grande do Sul, v. 20, n.1, p.73-86, 2011.

\section{Correspondência}

Eliza Penachi - Rua Sete de Setembro, 85, Santa Terezinha, CEP 85506-040, Pato Branco, Paraná, Brasil.

\section{(C) $(1)$ ( )}

This work is licensed under a Creative Commons Attribution-NonCommercial 4.0 International (CC BY-NC 4.0) 